\title{
Trigger action response plan development and optimisation at the Bingham Canyon Mine
}

\author{
KM Bakken Rio Tinto Kennecott Copper, USA \\ GK Chapin Rio Tinto Kennecott Copper, USA \\ MG Abrahams Rio Tinto Kennecott Copper, USA
}

\begin{abstract}
Slope movements are expected at the Bingham Canyon Mine due to the challenging slope angles mined to minimise strip ratios and maximise ore recovery. Trigger action response plans (TARPs) are a critical aspect of managing these movements in a mining operation. An effective TARP must balance production while safely managing the risk of mining in areas of slope movement. The challenges when developing efficient TARPs are defining appropriate triggers, trigger thresholds, and responses for specific areas of movement.

At the Bingham Canyon Mine, TARPs are developed by reviewing all available monitoring data and observations of slope behaviour. Trigger thresholds are developed specific to failure mechanism, previous experience, operational response time and monitoring capability. Responses are planned around potential runout scenarios and failure impacts to personnel, infrastructure, and equipment. Once in place, TARPs are continually optimised as the understanding of each failure improves and more information becomes available, or the mine layout changes. This paper presents three examples of how TARPs were developed for different failure mechanisms at the Bingham Canyon Mine.
\end{abstract}

Keywords: trigger action response plan, slope monitoring, slope failure, instability, risk management

\section{Introduction}

The Bingham Canyon Mine is located southwest of Salt Lake City, Utah, USA. The pit is approximately 1,300 m deep and spans more than $3.3 \mathrm{~km}$ across. Slope movements at Bingham Canyon Mine are expected during mining due to the challenging slope angles used to minimise strip ratios and maximise ore recovery. Furthermore, the complex geological and structural setting together with the impact of precipitation and snow-melt in spring make elimination of all slope movement uneconomical. Consequently, pit design is accepted by the business with the understanding that some slope movement is expected, provided that the risk can be safely managed. This risk is accepted and managed through detailed pit slope design and thorough pit-wide slope monitoring coverage managed by a dedicated operational geotechnical team.

Trigger action response plans (TARPs) are an important tool for managing slope movements. The purpose of a TARP is to define a range of trigger levels and the associated responses to be initiated in the event that a trigger level is reached. The challenge is ensuring the trigger thresholds are applicable to the failure mechanism and that the responses are achievable by the operation. The result is an instability-specific TARP which maximises production without compromising safety.

This paper describes how TARPs are developed at the Bingham Canyon Mine and how they are optimised as more information on slope behaviour becomes available and the mine layout changes. Three case studies are presented to illustrate how TARPs have been developed relative to different failure mechanisms.

\subsection{Monitoring network}

Management of slope movements at the Bingham Canyon Mine is the responsibility of the Operational Geotechnical Team. The team consists of eight engineers and four technicians. Slope monitoring is conducted 
with a network of six IDS ${ }^{\mathrm{TM}}$ and five GroundProbe ${ }^{\mathrm{TM}}$ radar units, which together provide full coverage of all active mining areas, plus overlap coverage between radars. The system ensures that active mining areas are continuously monitored in the event of an individual radar going offline. Additional slope monitoring systems include automated total stations and prisms, global positioning system units, InSAR, extensometers, high-resolution cameras and downhole instrumentation such as time domain reflectometers and in-place inclinometers.

\section{Trigger action response plan development}

TARP development at Bingham Canyon Mine follows slope movement from initial identification to ultimate stability or collapse. Initially, a pit-wide TARP is developed and used to manage new areas of slope movement, and/or smaller areas (typically 30-45 m, or two to three benches high) that pose a safety or production risk. As instabilities become more significant and pose an increasing risk to safety and production, an instability-specific TARP is developed. These are an optimised version of the pit-wide TARP which have triggers specific to the instability observed and responses customised to the mine layout around the specific failure and its mechanism. Developing and optimising instability-specific TARPs has both safety and economic benefits:

- Safety: accurate movement thresholds and more accurate predicted times to failure result in improved responses including evacuation and isolation of key areas. Furthermore, an improved understanding of the potential failure extents also results in more functional isolation areas.

- Economics: while pre-emptive evacuation or isolation of an area is sometimes necessary, it can also delay production for days or weeks ahead of an expected slope failure. An optimised TARP can prevent unnecessary loss of production through more accurately predicting both time-to-failure and the failure extents.

\subsection{Factors considered in trigger action response plan development}

When developing TARPs at Bingham Canyon Mine the following factors are considered:

- Failure mechanism: the failure mechanism is one of the most important considerations as it typically dictates the deformation trends expected as slope movement occurs. The failure mechanism also indicates what factors may initiate slope acceleration, such as blasting, precipitation, surface water infiltration, temperature fluctuations or excavation at the toe.

- Historic data: previous slope performance can be used to refine TARP triggers and for evaluating runout distances (e.g. failure may vary from dropping of benches to complete flow of material). Historical deformation trends from monitoring data show how a slope may behave prior to failure and trigger thresholds can be set accordingly. However, previous behaviour is not a guarantee of future behaviour.

- Monitoring coverage: both trigger thresholds and responses are dependent on available monitoring coverage. Real-time radar monitoring is critical to continued mining below any slope where movement is detected. For optimised TARPs to be in-place, both synthetic and real aperture radar are used to provide robust coverage of the area.

- Data quality: a factor to consider is the line-of-site of the radars as this will impact the magnitude of the displacement detected. In addition, noise from atmospheric interference or mining equipment must be accounted for and not cause false TARP escalation or de-escalation.

- Number of TARP levels: a TARP should have a sufficient number of levels such that each one has a clearly defined set of triggers and provides appropriate reaction time for the mine operations team to react to slope movement. Too many TARP levels can cause ambiguity between triggers and create redundant TARP levels. Typically, five TARP levels would exist as slope movement progresses from slight levels of deformation to failure. The general responses to these are shown in Table 1. 
Table 1 Typical mine responses and slope behaviour for different trigger action response plan levels

\begin{tabular}{|c|c|c|}
\hline $\begin{array}{l}\text { Trigger action } \\
\text { response plan level }\end{array}$ & Slope failure progression & Typical mine responses \\
\hline $0-1$ & Slight or no deformation & Routine operations and planning \\
\hline 2 & $\begin{array}{l}\text { Gradual slope deformation. } \\
\text { Constant rate (no } \\
\text { acceleration) }\end{array}$ & $\begin{array}{l}\text { Pause mining } \\
\text { Increase radar coverage; add tactical radar } \\
\text { Mining may be able to continue under } \\
\text { controlled conditions e.g. daylight only; periods } \\
\text { of no rainfall; spotter in place }\end{array}$ \\
\hline 3 & $\begin{array}{l}\text { Accelerated slope movement } \\
\text { (progressive phase) }\end{array}$ & $\begin{array}{l}\text { Remove personnel and equipment } \\
\text { Isolate area }\end{array}$ \\
\hline 4 & Failure expected & Maintain isolation \\
\hline 5 & Unexpected failure & Evacuate \\
\hline
\end{tabular}

\subsubsection{Triggers and responses}

Parameters used as triggers at the Bingham Canyon Mine include displacement, velocity, velocity ratio (VR) and inverse velocity. Different triggers are applicable to different TARP levels. Displacement, for example, is more applicable for defining lower TARP levels to indicate initial signs of movement rather than for predicting failure. This is because it is difficult to predict how much deformation a slope can undergo prior to failure. Triggers such as inverse velocity are more applicable for defining higher TARP levels since the accuracy in predicting failures with this method increases closer to time-of-failure.

Trigger thresholds are developed based on the failure mechanism, historical data, quality of monitoring data and the time required to implement any associated operational actions at the specified TARP level. Triggers used, their applicability at different TARP levels and typical thresholds are detailed in Table 2. TARPs are written such that each trigger level is prescriptive, but also to allow some engineering judgement to be applied.

Table 2 Suitable triggers and thresholds for different trigger action response plan levels

\begin{tabular}{|c|c|c|c|}
\hline Trigger & $\begin{array}{l}\text { Typical } \\
\text { thresholds }\end{array}$ & Comments & $\begin{array}{l}\text { Suitable trigger } \\
\text { action response } \\
\text { plan levels }\end{array}$ \\
\hline $\begin{array}{l}\text { Displacement } \\
(\mathrm{mm})\end{array}$ & $10-50 \mathrm{~mm}$ & $\begin{array}{l}\text { First indication of any slope movement. } \\
\text { Average daily displacements as well as } 7 \text { to } 14 \text { day rolling } \\
\text { averages are used. Displacement may be detected by radar, } \\
\text { prisms, GPS units, or visual inspections. }\end{array}$ & $0-1$ \\
\hline $\begin{array}{l}\text { Velocity } \\
\text { (mm/day) }\end{array}$ & $\begin{array}{l}2-20 \\
\mathrm{~mm} / \mathrm{day}\end{array}$ & $\begin{array}{l}\text { Used to assess average daily velocities as well as } 7 \text { to } 14 \text { day } \\
\text { rolling averages. Can be tracked by radar, prisms and GPS } \\
\text { units. Thresholds are dependent on failure mechanism. }\end{array}$ & $0-2$ \\
\hline $\begin{array}{l}\text { Velocity ratio } \\
\text { (VR) } \\
\text { (dimensionless) }\end{array}$ & $1.3-1.5$ & $\begin{array}{l}\text { VR = Current velocity divided by the previous velocity. This } \\
\text { identifies significant change (increase) in movement rate. } \\
\text { Critical to consider time frame being evaluated. Typically the } \\
\text { previous } 12 \text { hours or } 24 \text { hours are used for evaluating VR. }\end{array}$ & $2-4$ \\
\hline $\begin{array}{l}\text { Inverse velocity } \\
(1 / \mathrm{mm} / \text { day })\end{array}$ & $\begin{array}{l}\text { Failure } \\
\text { predicted } \\
\text { within } 1-3 \\
\text { days }\end{array}$ & $\begin{array}{l}\text { Important to extrapolate over different time periods to get } \\
\text { reliable trends and evaluate short-term changes. Typically } 3,6 \text {, } \\
\text { and } 12 \text {-hour extrapolations are used. Note that actual time-of- } \\
\text { failure is normally less than predicted time-of-failure. The } \\
\text { trigger threshold chosen must account for this, as well as the } \\
\text { time it will take the operation to respond. Only real-time radar } \\
\text { data is used for inverse velocity predictions at this TARP level. }\end{array}$ & $3-4$ \\
\hline
\end{tabular}


Specific triggers are also used when a failure is particularly sensitive to certain factors such as rainfall. Specific triggers may include:

- Intense rainfall. Typically, $25 \mathrm{~mm}$ in 24 hours would trigger a TARP 3 situation.

- Loss of real-time monitoring coverage. This would trigger a TARP 4 situation.

- Change in movement area outside of previously defined instability boundaries, i.e. an instability suddenly increasing in size or progressing along strike.

\subsubsection{Responses}

When defining responses to the defined trigger levels the following factors are considered:

- Mine layout and equipment: location of the instability and exposure of personnel and equipment are critical for determining appropriate isolation and responses to movement.

- Operational capability: this includes the capabilities of the monitoring team and equipment for triggering TARP escalation, as well as the time needed for operations to execute actions and responses. Any evacuation must be able to be undertaken in a timely, controlled and efficient manner.

- Runout analysis: runout analysis is used to estimate the extent of failure and, in turn, where isolation should be. Bingham Canyon Mine uses Fahrboschung analysis, and DAN3D ${ }^{\mathrm{TM}}$ numerical modelling to estimate failure extents. DAN3 $\mathrm{D}^{\mathrm{TM}}$ software uses a semi-empirical equivalent fluid approach to estimate failure runout extents (Frekaug 2014). Results of these models are used together with the mine layout to guide isolation extents.

\subsubsection{Trigger action response plan de-escalation}

A TARP should include clear definitions of when de-escalation can be allowed. At the Bingham Canyon Mine typical de-escalation requirements are:

- Steady state conditions (constant velocity) for a continuous time period (typically at least 24 hours) and/or:

- Clear regressive trend observed; or

- Suitable data acquired after/if the slope goes into phase ambiguity, i.e. when the slope is moving faster than the radar can detect. Typically, a minimum of 24 hours of high confidence data is required.

\subsubsection{Trigger action response plan optimisation}

Once a TARP has been implemented and used for an area, it is reviewed to determine if all triggers and responses were clear and effective. The more knowledge and previous experience with instability, the less uncertainty exists and the TARP can be updated to reflect these learnings. TARP optimisation can include changes to trigger thresholds, responses, isolation extents and general risk management approaches.

\section{Case studies}

Three case studies are presented where TARPs have been developed for different failure mechanisms in different areas of the pit. These are:

- Jordan Slide: A weak talus failure with metres of gradual deformation over four months.

- Lark Quartzite: A non-daylighting wedge which accelerates rapidly, responding to precipitation, blasting and toe excavation. 
- O-Slide: A complex, deep-seated movement block with deformation over years but which accelerates quickly in response to precipitation and mining activities such as blasting and toe excavation.

The observed deformation trends for the failure mechanisms are shown in Figure 1. TARP development for each instability is discussed in the following sub-sections.

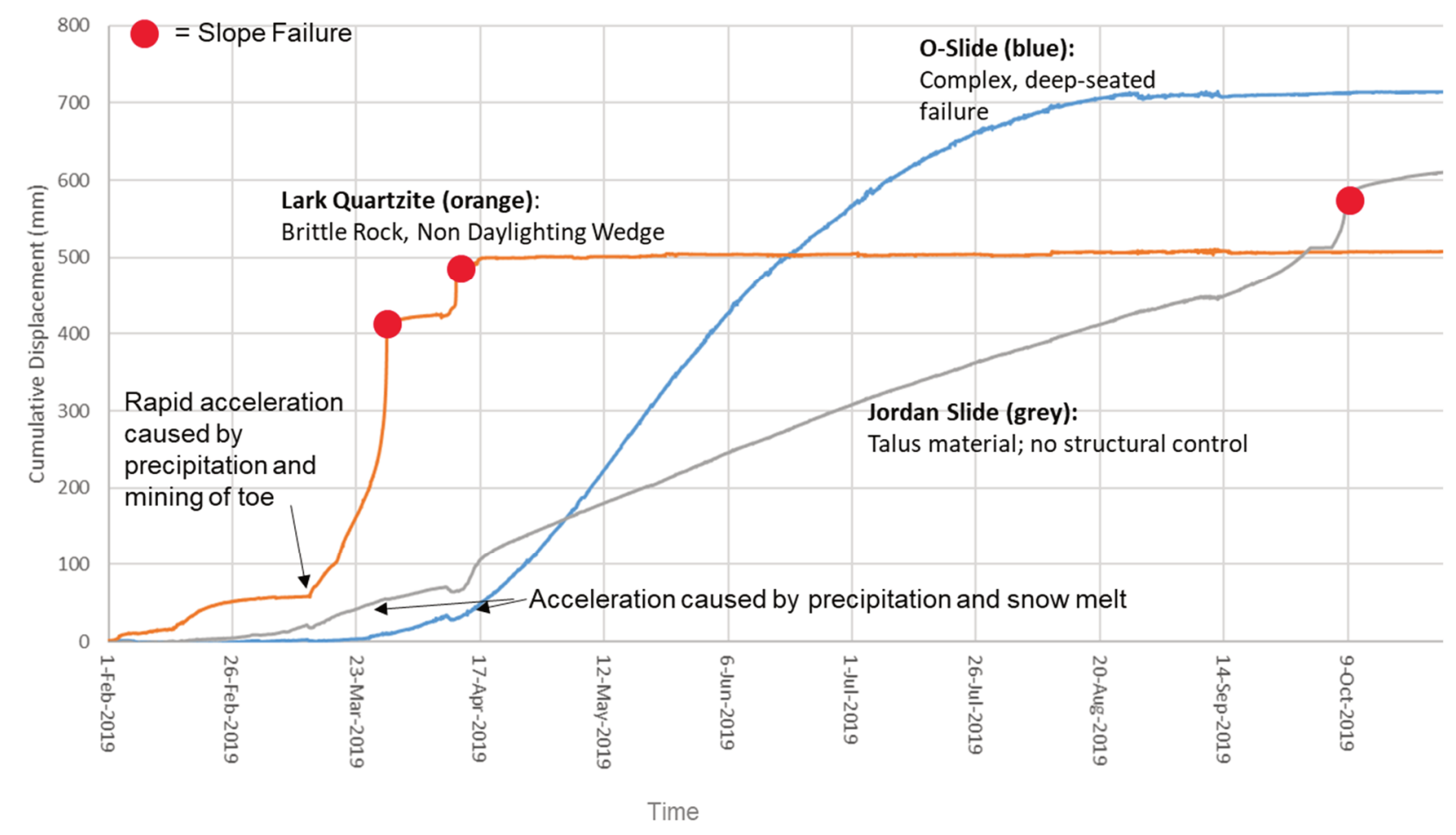

Figure 1 Cumulative displacement curves from radar data showing different behaviour of slopes with different mechanisms: kinematic instability (orange), weak talus material (grey), complex, deep-seated instability (blue)

\subsection{Case study: Jordan Slide}

The Jordan Slide area experienced a significant re-activation in October 2019. It is a historic instability which first initiated in 2005. Over time, the rock mass has degraded into a large soil-like mass with little visible intact rock. A large engineered berm at the toe of the instability protects the haul road that accesses the pit bottom and primary ore source. Deformation rates for the entire talus mass were less than $2.5 \mathrm{~mm}$ per day throughout 2018 and 2019. In the summer of 2019, radar monitoring detected increased movement in an upper area of the talus mass. The area of detected movement was approximately $160 \mathrm{~m}$ high by $140 \mathrm{~m}$ wide. Acceleration progressed steadily over the next four months until a failure event occurred on 8 October 2019. The failure mass was approximately $330,000 \mathrm{t}$. Material from the failure event was fully contained behind the engineered berm (Figure 2). The observed mechanism was a circular failure of soil-like material, which may have been exacerbated by water flowing through historic underground workings behind the slope. 


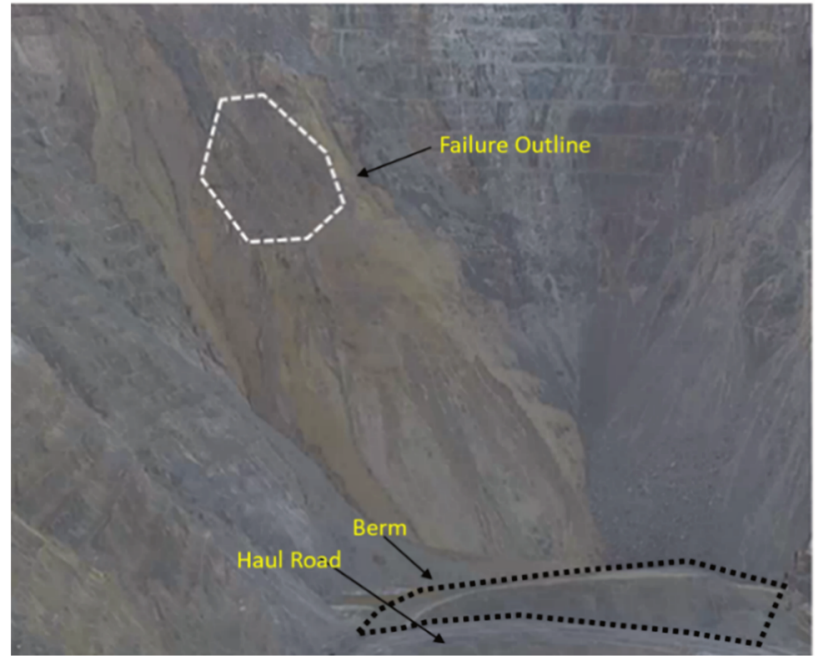

(a)

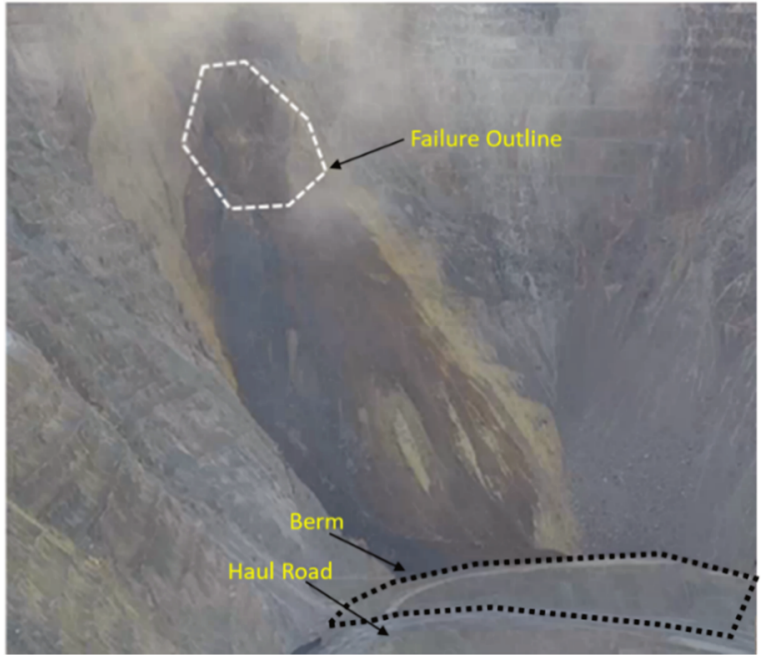

(b)

Figure 2 Jordan Slide (a) Prior to, and (b) Following the October 2019 failure. The dark-coloured failed material is fully contained behind the berm

\subsubsection{Trigger action response plan development}

Although no mining was actively taking place below the instability, pre-emptive closing of the haul road would result in significant production losses. Therefore, the key challenge of managing this instability was to develop a TARP which maintained access to the pit bottom for as long as possible without compromising the safety of personnel.

\subsubsection{Triggers and thresholds}

Triggers and thresholds were developed based on deformation trends from radar data. Starting in the spring of 2019, this slide had a sustained, constant deformation over a four-month time period of around $13 \mathrm{~mm}$ per day, over the last month before a rapid slope acceleration which resulted in slope failure. Because of this uniform behaviour, TARP 2 trigger thresholds were set at the lower bound limit of $18 \mathrm{~mm}$ a day, which is higher than most TARP 2 triggers used at Bingham Canyon Mine. TARP 3 and 4 triggers were based on a change in VR or inverse velocity.

\subsubsection{Responses}

Runout modelling was completed using DAN3D to determine failure extents and in turn guide suitable isolation areas for TARP levels. Both frictional and Voellmy scenarios were evaluated to determine the most likely and worst-case scenarios for the runout. A frictional scenario assumes that the debris flow will have a purely frictional resistance, while a Voellmy scenario assumes the failed mass has both a frictional and turbulent component. The instability mass was estimated using the current radar movement area with an assumed instability backplane of $37^{\circ}$. The modelled failure mass was $373,000 \mathrm{t}$. Runout results of the worst-case scenario indicated no deposition of debris on the haul road below (Figure 3 ). 


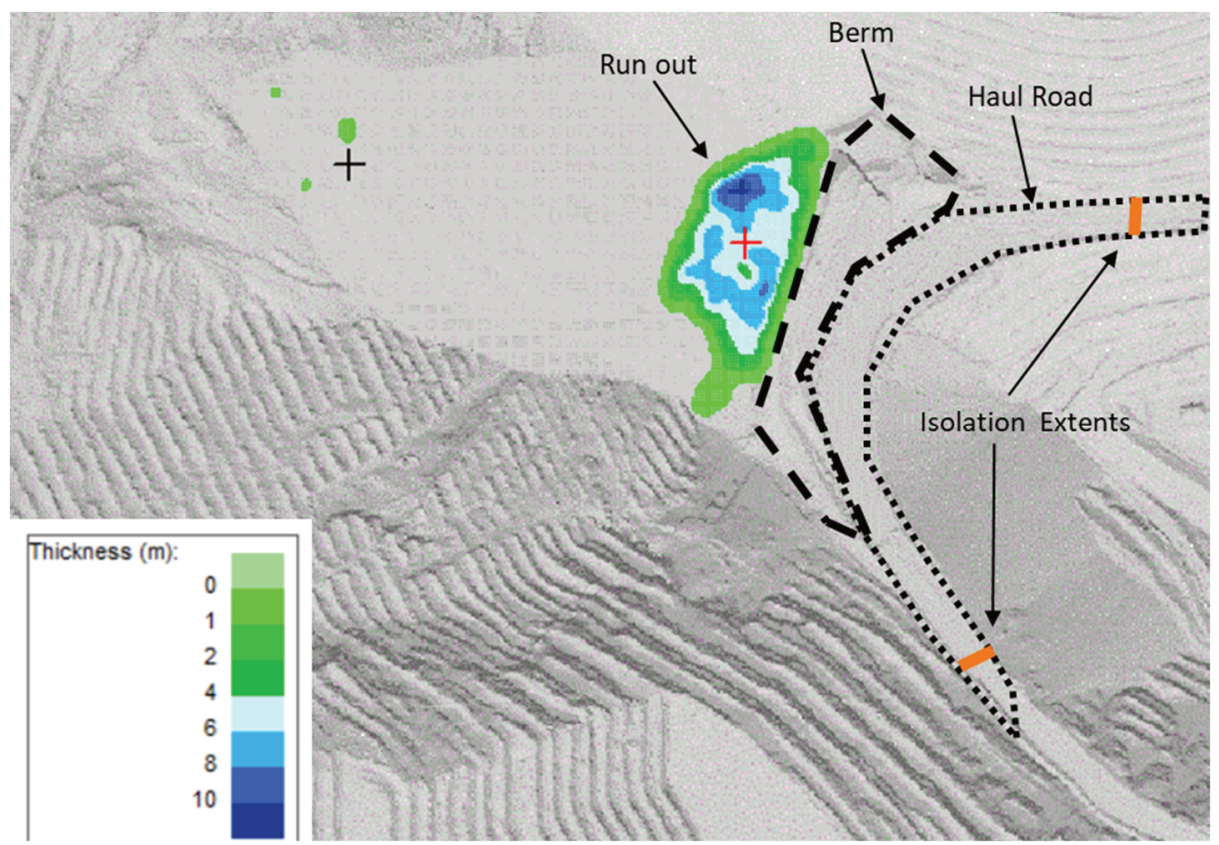

Figure 3 Plan view of the 'worst case' DAN3D runout scenario. All failed material is predicted to be constrained behind the berm

The runout analysis did not predict failed material reaching the haul road, however, given the proximity of the instability and model uncertainties, it was decided that the haul road should be closed prior to failure (TARP 4). No equipment beyond the haul road was at risk. Isolation extents are shown in orange on Figure 3. Implementing this isolation area meant closing the haul road and removing personnel from the pit bottom. Operations teams evaluated this and confirmed it could be done in less than three hours. This quick response time enabled an aggressive TARP to be developed, with key aspects as follows:

- Isolation of the area to occur at TARP level 4 rather than the more typical TARP level 3.

- TARP 4 controls are triggered when failure is predicted within 24 hours.

\subsubsection{Key learnings from the failure}

Following the failure, the TARP was re-evaluated and the following learnings were noted:

- The failure occurred quickly, taking place in less than a minute. It 'flowed', exhibiting Voellmy-type behaviour and therefore the 'worst case' runout scenario modelled was the most applicable.

- The failed material was fully contained behind the large berm as predicted in the runout analysis. Despite this, it is still considered appropriate to isolate the haul road at TARP 4 to account for the likelihood of a larger than modelled failure event.

- High-quality real-time monitoring data from multiple radars, clear communication throughout the event, and support of senior management to pause operations was essential to executing this TARP.

- From inverse velocity data, the actual failure time $\left(T_{f}\right)$ was always less than the predicted failure times $\left(T_{f p}\right)$, particularly within the last 22 hours prior to failure (Figure 4). Although all personnel were safely removed from the pit prior to failure, using $T_{f p}=24$ hours as a trigger was considered too aggressive given the inherent variability in any slope instability. Also, the slope went into phase ambiguity (i.e. movement rates were greater than the radars could detect) two hours prior to failure. During this time, no monitoring data is available and it is critical all personnel are safely evacuated prior to this occurring. Given these observations, revision of the TARP 4 threshold has since changed such that the TARP 4 trigger is now $T_{f p}=36$ hours rather than 24 hours. 


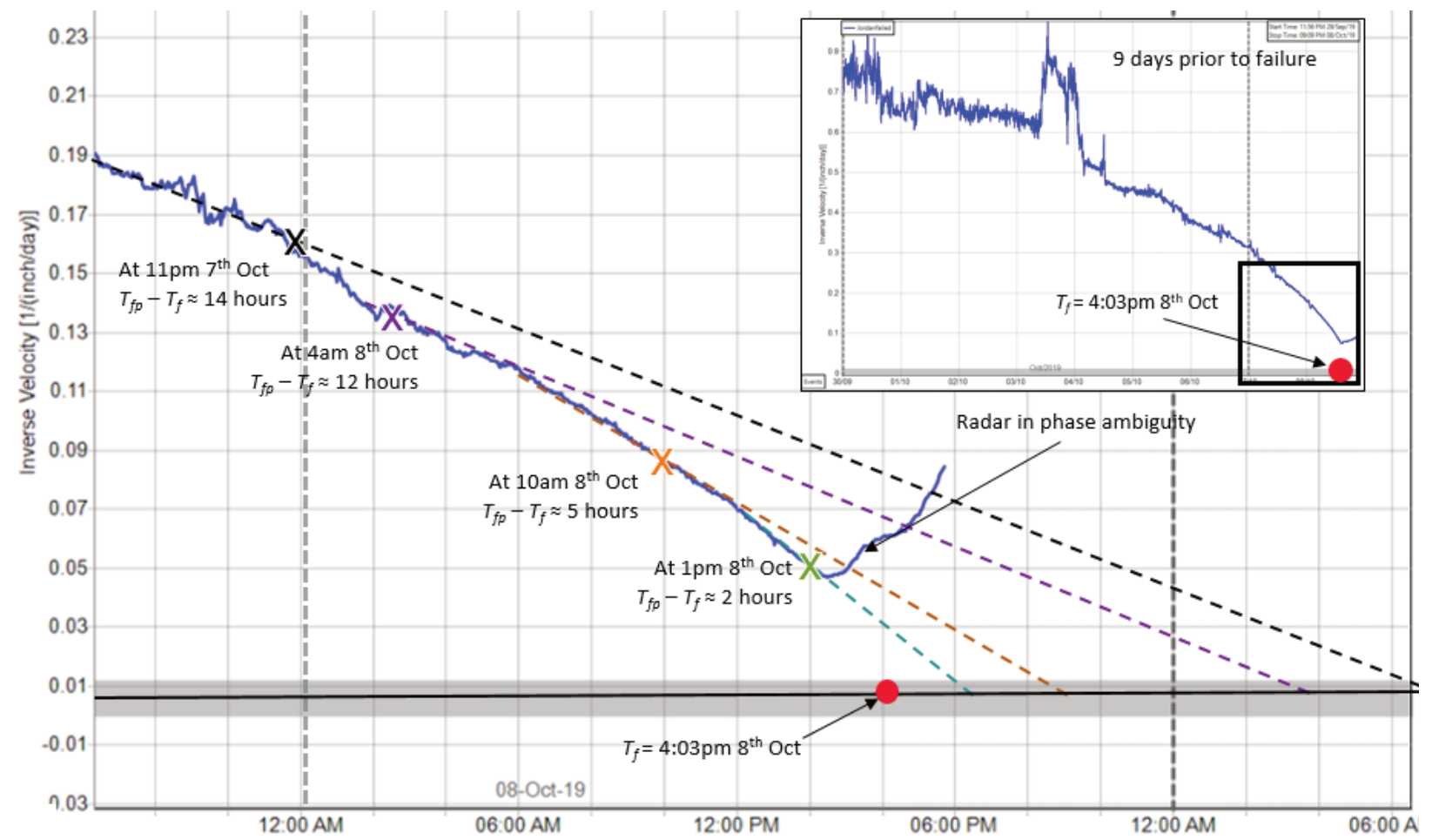

Figure 4 Inverse velocity images from ArcSAR radar. The inset shows the trend nine days prior to failure. Main image shows four time-to-failure predictions $\left(T_{f p}\right)$ in the 15 hours prior to failure. For every reading $T_{f p}>T_{f}$, the closer to time-of-failure, the more accurate the predictions become. Note: the slope went into phase ambiguity approximately two hours before failure occurred

A summary of the TARP triggers and responses for the Jordan Slide are given in Table 3.

Table 3 Jordan Slide trigger action response plan summary

\begin{tabular}{|c|c|c|c|}
\hline \multicolumn{4}{|c|}{ Jordan Slide TARP Summary } \\
\hline $\begin{array}{l}\text { Trigger level } \\
\text { description }\end{array}$ & $\begin{array}{l}\text { Trigger } \\
\text { level }\end{array}$ & Triggers & Response \\
\hline $\begin{array}{l}\text { Movement above } \\
\text { background }\end{array}$ & 1 & Detected movement $<18 \mathrm{~mm} /$ day & Routine operations and planning \\
\hline $\begin{array}{l}\text { Measurable } \\
\text { deformation beyond } \\
\text { anticipated values }\end{array}$ & 2 & $\begin{array}{l}\text { Displacement between } 18 \text { and } \\
114 \mathrm{~mm} \text { per day }\end{array}$ & $\begin{array}{l}\text { Mandatory radar coverage or escalate } \\
\text { TARP level }\end{array}$ \\
\hline $\begin{array}{l}\text { Acceleration of wall } \\
\text { movement }\end{array}$ & 3 & $\begin{array}{l}\text { Displacement }>114 \mathrm{~mm} / \text { day } \\
\text { and/or velocity ratio }>1.3\end{array}$ & $\begin{array}{l}\text { Isolate laydown areas below failure. } \\
\text { Minimum three radars covering area } \\
\text { including at least one tactical radar } \\
\text { Prepare for TARP } 4 \text { escalation }\end{array}$ \\
\hline $\begin{array}{l}\text { Potential failure } \\
\text { development }\end{array}$ & 4 & $\begin{array}{l}\text { Inverse velocity predicts failure } \\
\text { within } 36 \text { hours }\end{array}$ & $\begin{array}{l}\text { Remove all personnel from lower pit } \\
\text { Minimum three radars covering area } \\
\text { including at least one tactical radar }\end{array}$ \\
\hline Unexpected failure & 5 & Unexpected slope failure & Incident command established \\
\hline
\end{tabular}

\subsection{Case study: Lark Quartzite}

The Lark Quartzite failure is a non-daylighting shallow wedge with a plunge approximately parallel to the slope inter-ramp angle. The wedge is formed between persistent bedding faults and orthogonal joint sets. The area experienced several failure events from January to April 2019. Rapid acceleration events 
corresponded with precipitation, snow-melt, shovel mining and blasting at the toe. Failure events resulted in the significant offset of intact benches and overall degradation of the slope (Figure 5).

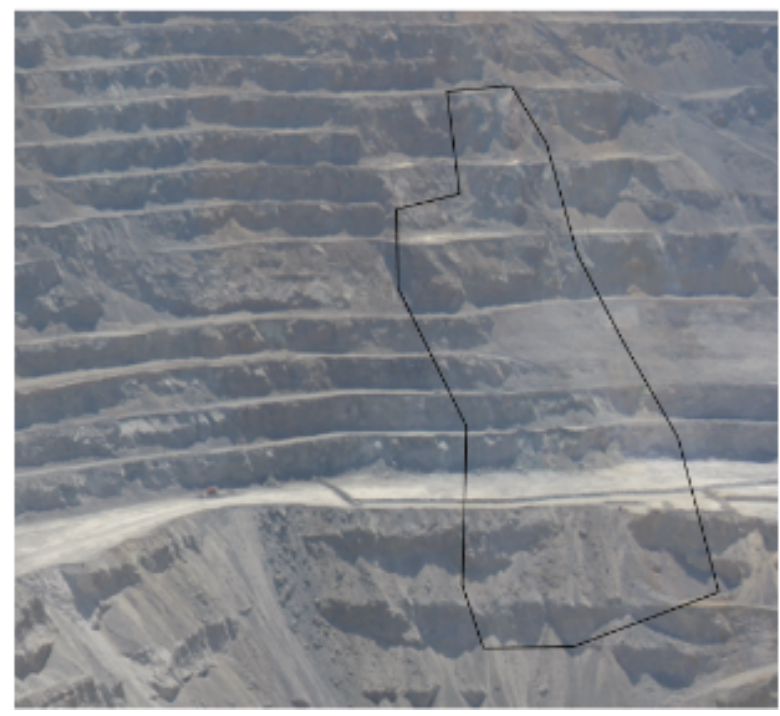

(a)

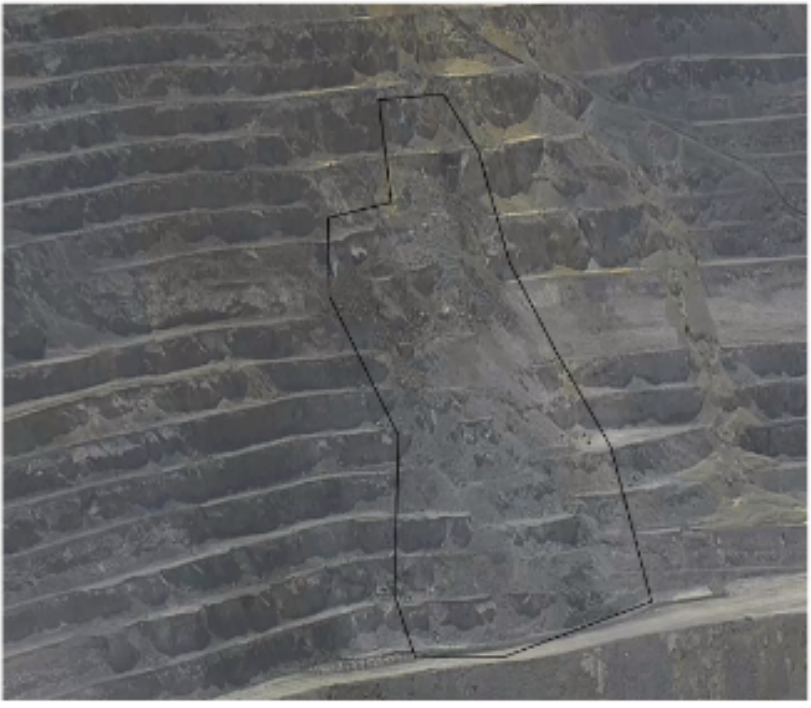

(b)

Figure 5 Lark Quartzite failure progression in (a) Fall 2018 to (b) Spring 2019

\subsubsection{Trigger action response plan development}

\subsubsection{Triggers and thresholds}

Triggers and thresholds were developed and refined using historical radar data and by understanding the failure mechanism. Observations from monitoring data used to optimise triggers included:

- Acceleration occurs rapidly and responds quickly to blasting, mining at the toe and precipitation.

- Time-to-failure from initial onset of movement was approximately 12 days. Four TARP levels need to be covered within this short time period. Consequently, TARP levels could increase daily or even be by-passed completely, giving the mine little time to respond.

\subsubsection{Responses}

A simple Fahrboshung angle analysis was used to determine a worst-case angle for runout extents for TARP 3 and 4 isolation. Isolation zones and lines were then designed according to these assumed runout extents. Since the mining cut below is narrow, the entire mining cut width was isolated prior to failure.

\subsubsection{Key points of the trigger action response plan}

The key challenge with this TARP was managing the potentially rapid onset of movement while maintaining both safe mining and haulage access below the failure for as long as possible. Key points of this TARP are:

- Isolation of the area must take place at TARP level 3 (not TARP level 4) due to rapid onset of failure.

- VR to be used as trigger for TARP 3 to identify the rapid acceleration increase. This must be done over a short interval (alarms are set over 3 and 6 hours) to proactively initiate the TARP level and maximise response time.

- Real aperture radar to be in-place at TARP level 2 as this experiences less atmospheric interference than synthetic radar and quicker scan times. 
- At TARP 2, a post-blast mining stand-down was implemented until constant or regressive trends were identified in monitoring data. A typical mining delay was between 12 and 24 hours and would be incorporated into the weekly mining plan.

The Lark Quartzite TARP emphasises escalation and de-escalation of TARP levels. Rapid acceleration means the Lark Quartzite failure can potentially bypass TARP 2 or 3 before progressing to TARP 4 . To plan for the rapid acceleration, tight alarms were set on radar units. Alarm thresholds set are tighter than those specified in the TARP to provide the Operational Geotechnical Team sufficient notification of any changes in slope behaviour. Summary of the TARP triggers and responses are given in Table 4.

Table 4 Lark Quartzite trigger action response plan summary

\begin{tabular}{|c|c|c|c|}
\hline \multicolumn{4}{|c|}{ Lark Quartzite trigger action response plan summary } \\
\hline $\begin{array}{l}\text { Trigger level } \\
\text { description }\end{array}$ & $\begin{array}{l}\text { Trigger } \\
\text { level }\end{array}$ & Triggers & Response \\
\hline $\begin{array}{l}\text { Movement above } \\
\text { background }\end{array}$ & 1 & $\begin{array}{l}\text { Detected movement } \\
<2.5 \mathrm{~mm} / \text { day }\end{array}$ & Routine operations and planning \\
\hline $\begin{array}{l}\text { Measurable } \\
\text { deformation beyond } \\
\text { anticipated values }\end{array}$ & 2 & $\begin{array}{l}\text { Movement between } 2.5 \\
\text { and } 5 \mathrm{~mm} \text { per day }\end{array}$ & $\begin{array}{l}\text { Pause mining and blasting below instability } \\
\text { until regressive or constant trend observed. } \\
12 \text { hour stand-down after blasting to ensure } \\
\text { no continued acceleration } \\
\text { No mining during heavy rainfall } \\
\text { Tactical radar to be in-place in addition to } \\
\text { synthetic aperture radar. }\end{array}$ \\
\hline $\begin{array}{l}\text { Acceleration of wall } \\
\text { movement }\end{array}$ & 3 & $\begin{array}{l}\text { Displacement }>5 \mathrm{~mm} / \mathrm{day} \\
\text { and/or velocity ratio }>2.0\end{array}$ & Isolate immediate area below movement area \\
\hline $\begin{array}{l}\text { Potential failure } \\
\text { development }\end{array}$ & 4 & $\begin{array}{l}\text { Inverse velocity predicts } \\
\text { failure within two days }\end{array}$ & Expand isolation and prepare for failure event \\
\hline Unexpected failure & 5 & Unexpected failure & Incident command established \\
\hline
\end{tabular}

\subsection{Case Study: O-Slide}

The O-Slide is a complex, deep-seated instability along the south wall of the pit. It is bounded to the east by the Copper Centre Fault. In the upper slope, the O-Slide sits in sediments with movement along the Brooklyn fault. Lower slope movements occur in monzonite along multiple shear surfaces between 65 and $130 \mathrm{~m}$ below surface. The Giant Chief Fault persists through the O-Slide block (Figure 6).

Movement was first detected in 2003. In May 2011, large deformation rates were observed along with cracking at the toe of the area. This was likely due to high precipitation and snow-melt infiltration into the area. Following this movement, a $30 \mathrm{~m}$ high toe buttress was constructed. During 2015, depressurisation occurred below the O-Slide block through the development of the underground drainage gallery, and no subsequent deformation was detectable from radar monitoring. However, in July 2018, low rate deformation was observed as mining commenced at the toe. Acceleration occurred in January 2019 and again in April 2019 following significant rainfall and snow-melt. A regressive trend was observed in July 2019 which coincided with a period of dry weather, a stop in mining at the toe and construction of a toe buttress. Mining of the Slice 1 pushback commenced in 2018 which helps unload the top and will eventually mine out the O-Slide (Figure 6). 


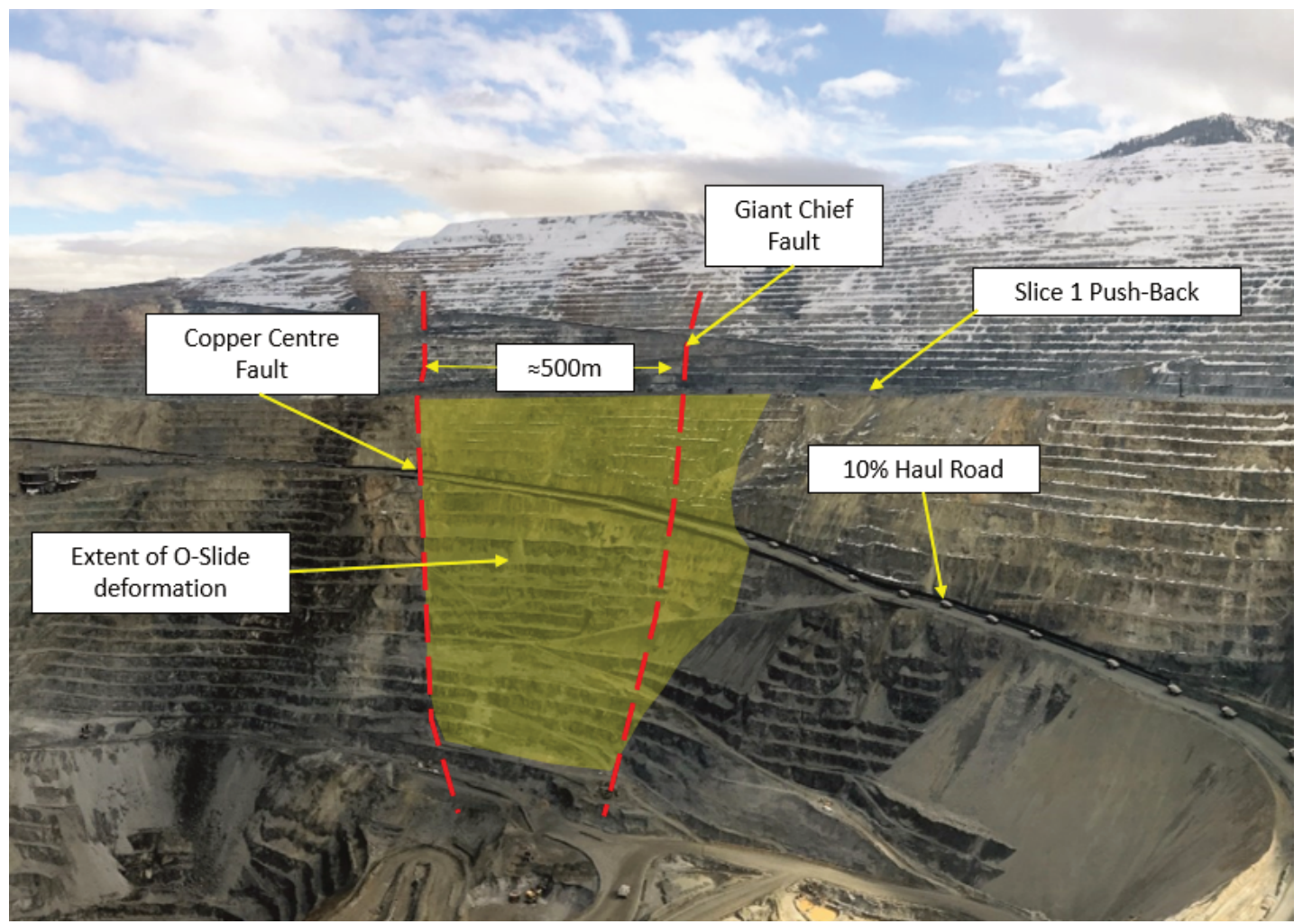

Figure 6 The O-Slide deformation area along the south wall

\subsubsection{Trigger action response plan development}

The O-Slide poses a significant safety and economic risk to Bingham Canyon. A failure event could potentially result in loss of future ore and access to the pit bottom. The TARP developed was one of the tools used in managing this movement. The challenge was ensuring lower TARP levels were triggered early enough that remediation actions could be taken to prevent the O-Slide from progressing towards failure while also maintaining production from the lower pit. Radars, prisms, GPS units, inclinometers, time-domain reflectometers, and vibrating wire piezometers were all used to monitor the O-Slide.

\subsubsection{Triggers and thresholds}

The instability-specific TARP was developed in 2018 when re-activation was observed. It was developed using historical prism and radar data with GPS units and inclinometers to verify surface movement trends. Observations from monitoring data were as follows:

- Onset of movement appeared to be triggered by mining of the 4690 bench at the toe in June 2018 , Onset of movement was gradual with velocities averaging $0.8 \mathrm{~mm} /$ day. Increased acceleration was observed in December 2019 as the 4640 and 4590 benches were mined and rates increased to approximately $50 \mathrm{~mm} /$ day. These trends suggested a gradual and delayed response to removal of toe support, as shown by the plot of radar movement and the tonnage mined (Figure 7).

- Large amounts of long-term, gradual deformation takes place during the spring, suggesting the O-Slide is sensitive to precipitation and surface water infiltration.

- Acceleration occurs gradually as observed by the long-term trends. This means acceleration is only detectable over days to weeks rather than hours, and TARP trigger thresholds needed to account for this. VRs had to be evaluated over long time periods (up to seven days) to confirm acceleration.

- Five TARP levels were considered necessary to cover the range of movements over the longer time periods. 


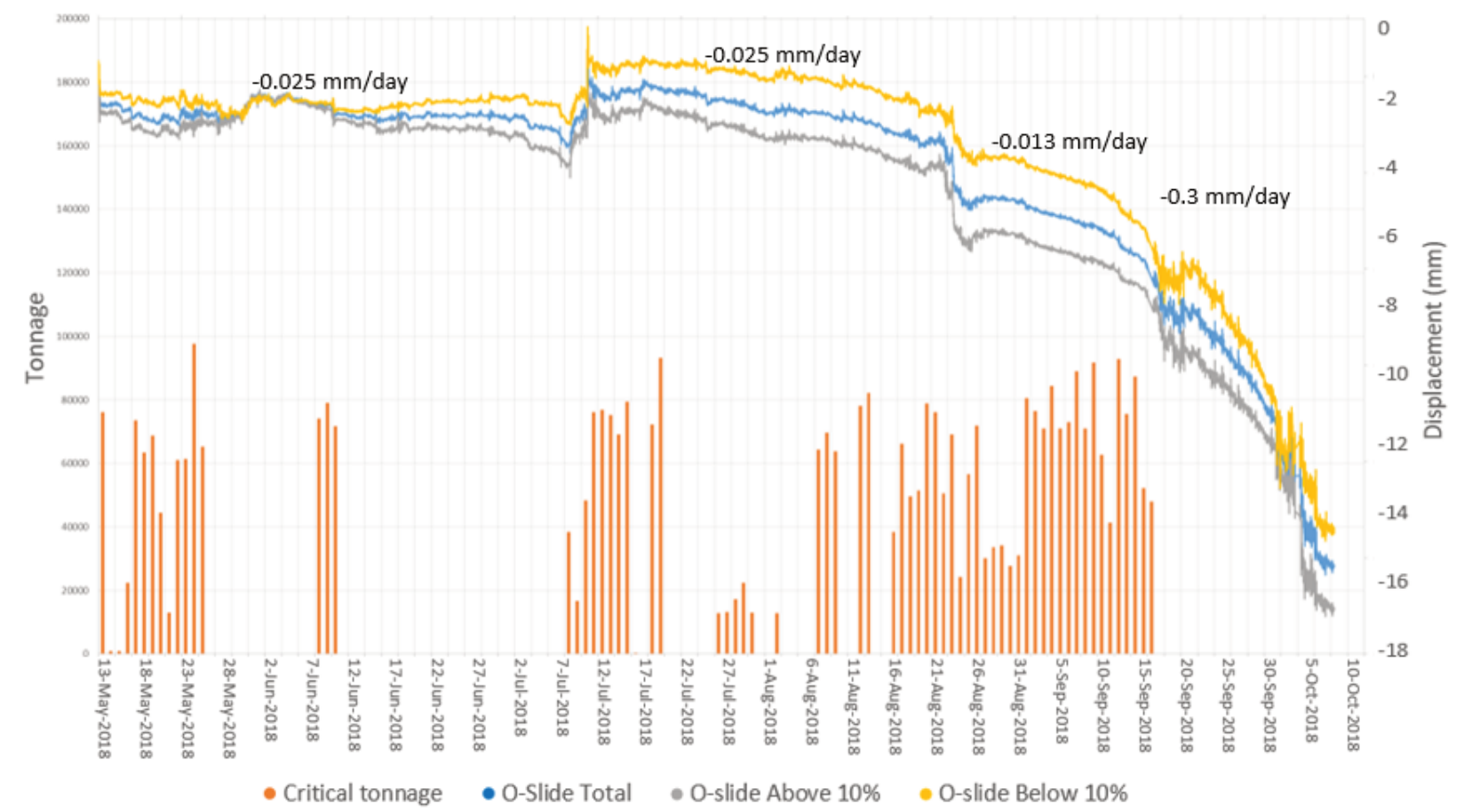

Figure 7 Radar movement from May 2018 to October 2018 showing O-Slide displacement in response to tonnage mined at the toe

\subsubsection{Responses}

The key response added into this TARP was to pause mining at TARP level 2. This enables proactive slope management actions to be taken before the movement progressed towards failure. Such a large instability may take time to regress or progress, therefore enough time is required to evaluate and implement options to prevent failure. Given the economic risk of a failure, it was necessary to undertake remediation action at TARP level 2. In this case, when acceleration occurred in March 2019 and TARP 2 was triggered, remediation actions were taken and eventually, the O-Slide showed a regressive trend in July 2019. Remediation actions taken included:

- Pause mining and step-in to prevent removing any further toe support.

- Accelerate mining of the Slice 1 pushback to un-weight the top of the instability.

- Construct buttress to increase toe support.

The O-Slide TARP emphasises the importance of suitable triggers for TARP levels 1 and 2 . The tight triggers ensured that the movement was addressed as soon as possible, minimising risk for a larger acceleration or possible failure event. It also emphasises the importance of customising TARP 2 triggers to the instability, since TARP 2 impacts on mine plan and ore delivery can be significant.

Summary of the TARP triggers and responses are given in Table 5. 
Table $5 \quad$ Key aspects of the O-Slide trigger action response plan

\begin{tabular}{|c|c|c|c|}
\hline \multicolumn{4}{|c|}{ O-Slide trigger action response plan summary } \\
\hline $\begin{array}{l}\text { Trigger level } \\
\text { description }\end{array}$ & $\begin{array}{l}\text { Trigger } \\
\text { level }\end{array}$ & Triggers & Response \\
\hline $\begin{array}{l}\text { Movement above } \\
\text { background }\end{array}$ & 1 & $\begin{array}{l}\text { Detected movement } \\
<0.5 \mathrm{~mm} / \text { day }\end{array}$ & Routine operations and planning \\
\hline $\begin{array}{l}\text { Measurable } \\
\text { deformation beyond } \\
\text { anticipated values }\end{array}$ & 2 & $\begin{array}{l}\text { Detected movement } \\
>1.3 \mathrm{~mm} / \text { day }\end{array}$ & $\begin{array}{l}\text { Pause O-Slide mining } \\
\text { Distribute level } 3 \text { \& } 4 \text { Isolation zone maps } \\
\text { Report rates daily } \\
\text { Generated detailed monitoring review monthly }\end{array}$ \\
\hline $\begin{array}{l}\text { Acceleration of wall } \\
\text { movement }\end{array}$ & 3 & $\begin{array}{l}\text { Detected movement } \\
>19 \mathrm{~mm} / \text { day or velocity } \\
\text { ratio }>1.5 \text { over } 48 \text { hours }\end{array}$ & $\begin{array}{l}\text { Remove personnel } \\
\text { Isolate TARP Level } 3 \text { isolation zone and verify safe } \\
\text { travel routes } \\
\text { Use spotters and test radars daily } \\
\text { Daily monitoring reports generated }\end{array}$ \\
\hline $\begin{array}{l}\text { Potential failure } \\
\text { development }\end{array}$ & 4 & $\begin{array}{l}\text { Trend toward failure } \\
\text { within seven days }\end{array}$ & $\begin{array}{l}\text { Remove personnel and Isolate TARP Level } 4 \\
\text { isolation area } \\
\text { Prepare for failure event }\end{array}$ \\
\hline Unexpected failure & 5 & Unexpected failure & Incident command established \\
\hline
\end{tabular}

\section{Conclusion}

TARPs at Bingham Canyon Mine are developed and optimised to ensure the safety of personnel while reducing impacts to production. Key learnings from the development and optimisation of TARPs include:

- Generic site-wide TARPs must be developed to identify appropriate actions for any unexpected or unknown areas of slope deformation.

- Slope-specific TARPs should be developed as early as possible such that if/when movement increases, there is a clear and well-defined plan for all teams to follow.

- Slope failure mechanism and behaviour must be accounted for when defining trigger thresholds. Shallow, kinematic failures may accelerate rapidly from a TARP 1 to a TARP 4 level over days or even hours. This results in little time to respond operationally. Larger or deeper-seated failures may accelerate gradually allowing more response time.

- Triggers should reflect historical time series behaviour and should be correlated for potential causes of failure such as heavy rainfall, blasting or excavation at the slope toe.

- Displacement, velocity and visual inspections are suitable triggers for defining lower TARP levels, typically up to level 2 . Velocity ratio and inverse velocity become increasingly important for defining TARP levels 3 and 4.

- Time-to-failure predictions from inverse velocity plots may reduce over time, i.e. the inverse velocity plot is not linear and failure may occur sooner than predicted. This is critical if using inverse velocity as a trigger for isolating an area.

- A de-escalation process should be incorporated into TARPs such that it is clear when TARP levels can be reduced should an instability show regressive behaviour. 
- Monitoring capability and redundant coverage must be accounted for, especially when optimising TARPs. If operating below an area of movement, Bingham Canyon Mine requires a minimum of two real-time radar units monitoring any the area.

- Runout scenarios should be completed and then a sensitivity analysis should be done to predict a 'worst case' outcome. Additional space must be added between the predicted failure extents and the isolation areas to account for unexpected slope behaviour. Different isolation areas can be used for equipment and personnel.

- Historical instabilities of a slope should be considered when evaluating runout distances (e.g. dropping of benches versus flow of material). However, previous behaviour is not a guarantee of future behaviour.

- Responses must consider the operational capability of the mine and the reality of implementing the required isolation areas once a new TARP level is reached.

- Alarm thresholds on monitoring equipment do not have to be the same as those in the TARPs. The geotechnical team at Bingham Canyon Mine set tighter radar alarms than exist in the TARP levels to ensure slope movements are proactively managed. This is especially important for those instabilities which respond rapidly to blasting, excavation and precipitation.

- Effective communication and collaboration with multiple teams within an organisation are essential when developing and implementing TARPs. New or revised TARPs must be reviewed and signed off by all persons accountable for the different responses required.

\section{Acknowledgements}

The authors thank the other members of the geotechnical team at Bingham Canyon Mine who helped develop the TARPs, compiled the data and continue to maintain all the monitoring equipment. We also wish to thank Martyn Robotham and Sarah McAuley for their review and suggestions.

\section{Reference}

Frekaug, M 2014, Run-out Modelling of Debris Flows, MSc thesis, Norwegian University of Science and Technology, Trondheim. 